\title{
On the English Translation of Chinese Modern Essays From the Perspective of Cognitive Context: A Case Study of Zhang Peiji's English Translation of Chinese Essay “巷”
}

\author{
Jianwei Zheng \\ School of Foreign Languages, Wuhan Institute of Technology, No.206, Guang Gu Yi Lu Road, Wuhan 430205, China \\ E-mail: 15100901@wit.edu.cn
}

Received: 05-04-2016

Published: 01-09-2016
Accepted: 17-06-2016

doi:10.7575/aiac.ijalel.v.5n.5p.96
Advance Access Published: July 2016

URL: http://dx.doi.org/10.7575/aiac.ijalel.v.5n.5p.96

\begin{abstract}
For an English translation of Chinese modern essay to be comprehensible and acceptable to English readers while exhibiting the particularity of Chinese essays, it's necessary to discuss the differences between the cognitive contexts in the mind of Chinese and English readers in their appreciation of Chinese modern essays in Chinese and English respectively. By dealing with such differences, this paper attempts to analyze the translation strategies adopted by Zhang Peiji in his translation of Chinese essay “巷” ( “The Lane"), which is also evaluated from the perspectives of rhythm, style and spirit in the end of the paper.
\end{abstract}

Keywords: Chinese modern essay; cognitive context; translation; Zhang Peiji; rhythm

\section{Introduction}

As many well-written English essays have been available to Chinese readers through the efforts of Chinese translators, Chinese essays should also been made available to English readership to make culture exchange and to share the richness of Chinese essay literature. However, difficulties abound in the translation of Chinese modern essays due to the differences of writing style and cultural background between English and Chinese languages.

The literature on English translation of Chinese modern essay can be divided into three classes: the first class generally addresses the equivalence of form and content (e.g., Zhu, 2000), the second class discusses the employment of specific translation strategies, methods or techniques (e.g., Tang, 2001; Hu \& Li, 2009:182-186), and the third class usually expounds from the perspective of translation theories like dynamic equivalence and translation aesthetics (e.g. Lai, 2009; Zhang, 2011). All of them are elaborated from the perspective of translator. This paper, however, explores for the first time the resolution of the clash between Chinese and English readership conventions (perception, expectation and appreciation conventions of readers). That is to say, this research is initiated from the perspective of the reader instead of the translator. Besides, the paper is also the first one to discuss the English translation of Chinese modern essays from the standpoint of cognitive context, specifically the strategies to deal with the shortage of background assumption to construct cognitive context for English reader to, firstly, comprehend and, secondly, appreciate the translation.

Context in terms of cognitive perspective was first explored by Sperber and Wilson who defined it as "the set of all the facts that an individual can perceive or infer: all the facts that are manifest to him" (Sperber \& Wilson, 2001:39), supported by Vandepitte (1989), Xiong (1996) and Ramos (1998). Each individual will select each unique set of assumptions to construct a context to understand each utterance. According to Sperber and Wilson, the interpretation of the previous utterance constitutes the preliminary context for the next utterance to be processed. Besides, three extensions of this preliminary context may be needed to understand the utterance. They are the interpretation of earlier utterances in the verbal communication, the encyclopedic knowledge or information of concepts in the context or in the processed assumption and information about the situation of verbal communication (Sperber \& Wilson, 2001:140). In order to realize a successful communication as easy as possible, the context used by the writer/speaker for the utterance should be as accessible as possible to the reader/hearer. The used context of Chinese essays can always be easily accessed to Chinese readers for most of the background assumptions to construct and deconstruct the context of both the writer and the readers are similar due to the commonness of encyclopedic knowledge, cultural, social, ideological, etc. Consequently, gaps between the cognitive contexts of Chinese essay readership and English essay readership should be bridged by an adequate translation strategy. Translators should provide English readers with additional information to offset the lack of some background assumptions necessary to understand the text, or make some clarification of the text, or arrange the content in an English way, all for the purpose of facilitating English readers to construct a required cognitive context to appreciate Chinese essays. 
This paper will analyze English readers' probable shortage of background assumptions to construct necessary cognitive contexts to understand the Chinese essay “巷”, and illustrate how the translator Zhang Peiji deal with this shortage in terms of content and structure, and then evaluate his translation from the perspectives of rhythm, style and spirit.

\section{From Comprehension to Appreciation: The Shortage of Background Assumptions to Construct Necessary Cognitive Contexts to Read Chinese Essays}

Fundamentally, any translation should read fluently and comprehensibly to native language speakers. Though there exist many differences between Chinese and English essay readership, proper translation can transform the source text in Chinese to a translation acceptable, i.e., understandable to the English readership. So first of all, the English essay readership should be compared to Chinese one to discover both of their specific and unique internalized expectations. But to be understandable is just a basic requirement for a translation, especially for a translation of literature. The ideal goal of essay translation should be to allow English readers to appreciate the particular aesthetics and artistry of Chinese essays which are enormously different from English essays.

This Chinese essay “巷” boasts a great number of idioms, cultural nouns, sentences and discourse features which are unique to Chinese essay authorship (here it means "way of writing") and readership (here it means "reading preference and norm"). These expressions are full of beauty, elegance and simplicity to Chinese readers. How to make them understandable to English readers? To make it readable, let us first of all analyze the shortage of background assumptions of English readers which are the basic elements to construct cognitive contexts to understand the essay “巷 ". It should be noted that Chinese authorship advocates and readership expects implicitness and vagueness in the expression while English authorship worships and readership prefers explicitness and logicalness in the expression (Wang 2006:1). Consequently, English readers will suffer from understanding the translation of Chinese essays due to the shortage of such aesthetic assumption of essay readership. Specifically, in terms of vocabulary, there are three kinds of culture-specific words or phrases in this essay difficult to find English equivalents. The first kind is proper noun, such as “江南” (literally meaning River South) “老虎灶” (literally meaning Tiger Stove). The second kind is the common noun, such as “深闺”(literally meaning Deep Boudoir) and “红尘” (literally meaning Red Dust). The third kind is adjective, such as “古朴” (literally meaning Primitively Simple) and “深居简出” (literally meaning Secluded Dwelling and Seldom Going Out). Many of such words don't have an exact connotation. They addict themselves to the ambiguity of meaning which helps to build up a powerful artistic perception and emotion in the heart of readers ant the writer himself. What information the text provides is actually not important at all. In terms of sentence, Chinese essays look illogical sometimes such as when there is no subject, object or predicate in the sentence or the collocation of sentence elements seems improper in meaning (Wang 2006:2). This is due to the fact that Chinese writer/reader doesn't pay much attention to how the correct words with exact meaning correctly collocate and combine into a sentence. It's quite different from English authorship/readership which deliberately supplies every necessary element to realize grammatically-correct sentences. In terms of discourse, Chinese writing always displays itself to be loose-structured in form whereas English writing gives great importance to cohesion and coherence which make the text strictly-structured in form. Chinese writing, especially Chinese poetry and essay, always arrange the text by placing the images one after another. Links are not needed as long as the image following the previous one can naturally conjure up in the readers a part of the whole picture or certain artistic sentiment/perception which are always the purpose of the poetry or many essays like this one “巷”.

All of the above tells the background assumptions of Chinese essay readership which differs greatly from the English essay readership. It can be concluded that Chinese readers aesthetically assume that an essay should be ambiguous and implicit in meaning or content, thus leaving a big room for artistic perception, and should be loose-structured, thus serving as a spiritual relaxation for readers. Such major aesthetic assumptions are actually vacant in the mind of English readers, thus making the translation, if literally rendered, difficult to be understood and appreciated.

\section{Strategies to Deal with the Shortage in Zhang Peiji's Translation of this Essay.}

Considering such shortage of background assumptions of Chinese essay readership, we are going to look at how the famous Chinese essay translator Zhang Peiji produce a translation understandable and even appreciable to English readers. The 95-year-old professor is one of the most celebrated translators in China, especially crowned in English translation of Chinese modern essays which is represented by his translation series of Selected Modern Chinese Essays. The tetralogy has won a popular compliment both in translation profession and academic field (Zhu, 2000; Han \& Wang, 2004). So it's believed that a review of Zhang's translation may indicate some effective and adequate solutions that can ever be employed to the fullest to tackle the shortages of background assumption in vocabulary, sentence and discourse common in English translation of Chinese modern essays.

As we have discussed three aspects of shortage in the previous part, we will analyze his translation strategies from these aspects. With regard to words, several strategies are adopted by this translator. First, the technique of paraphrasing:

(1) 这种巷，常在江南的小城市中，有如古代的少女，躲在僻静的深闺，轻易不肯抛头露面。

Often tucked away in a small town south of the Yangtse River, the lane, like a maiden of ancient times hidden away in a secluded boudoir, is reluctant to make its appearance in public.

In this sentence, the translator used paraphrasing to ensure the foreign readers can understand culture-specific words, though the cultural elements have totally vanished through paraphrasing. This lose of meaning sometimes is necessary since most foreign readers don't have enough background assumptions to understand these culture-bound words. The word “江南” always allow us to think of drizzle, beauty, etc, such as in “日出江花红胜火，春来江水绿如蓝，能不忆 
江南” and “正是江南好风景，落花时节又逢君”. Actually it is filled with profound cultural connotation which is hard to render. It is just paraphrased into "south of the Yangtze River" to make it understandable to foreign readers. The ambiguous cultural meaning has been transformed into a specific geological location which exactly complies with foreign readership convention requiring the exactitude of meaning. And “深国” which refers to a forbidden room of the maiden has been translated into "secluded boudoir", which generally expressed the situation and nature of the room.

Besides, transliteration plus explanation has appeared here and there in the translation. Here the following are two examples.

\section{(2)…....颓然地走到老虎灶上去提水}

shuffling languidly in their slippers towards a Laohuzao, the shop specializing in selling boiled water...

(3) 它可能是一条现代的乌衣巷.......

It may be a modern version of $\mathrm{Wu}$ Yi Xiang, a special residential area of nobility in the Jin Dynasty southeast of today's Nanjing.

Chinese readers are quite familiar with the two words, namely “老虎灶” and “乌衣巷” as they have built up many background assumptions related to the words in question. In order to maintain the uniqueness of the two matters and to make them understandable, Zhang transliterates them and adds explanation to them. As both words don't contain much ambiguous cultural meaning, the elaborate explanation is very adequate for foreign readership to understand them.

Third, domestication also occurs somewhere in this passage. Domestication here means the culture-specific elements in the original text are eliminated and replaced by native expressions familiar to target readers. For example:

(4) 隔绝了市㢈的红尘......

Cut off from the hustle and bustle of busy cities.

In this example, this very word “红尘” has been converted into an English expression "hustle and bustle", which technique can supply some value of English culture to the loss of the cultural meaning specific to Chinese language. The word “红尘” can be frequently read in ancient Chinese poets, such as “一骑红尘妃子笑，无人知是荕枝来”. If it's literally translated into "red dust", however, the English readers who lack related background assumptions will definitely be confused, thus communication will become a failure.

In translation, the translator also employs simplification to extract the basic referential meaning. As a result, noble words with rich literary clothes transform themselves into plain and simple words, such as:

(5) 墙里常是人家的竹园，修竹深深，天籁细细…...

Inside the walls are residents' gardens with dense groves of tall bamboos as well as soft sounds of nature.

The above target sentence of (5) sees the missing of poetic sensation in the original three words: “人家”, “修竹”, “天籁 ”. The word “人家” also contains rich cultural meaning and often associates us with a "cozy and happy family living a simple life" just as in the poems “小桥流水人家” and “远上寒山石径斜，白云深处有人家”. Zhang Peiji translated it into "residents", a very neutral word without poetic aesthetics but it's easy to understand for English readers. Similarly, the noble words “修竹” were rendered “tall bamboos" and “天籁” simply rendered "sound of nature”. In order to realize comprehensibility, both English phrases have lost the elegance and nobility to which the Chinese words are bound.

Fifth, concretization has also been used. Concretization here means making clear abstract words with unclear or illusive meaning. An example as following:

(6) 可是重门叠户，讳莫如深.......

Where each family, secluded behind closed doors......

(7) 是城市喧器扰攘中的一带洞天幽境.......

It is a heavenly abode in the midst of confusion.

The three Chinese phrases actually don't have very exact meaning though they refer to some state known to Chinese readership. Without such assumption, English readers can hardly understand them, to say nothing of appreciation. Consequently, Zhang must concretize these words, i.e., to make their meaning specific and exact. “重门叠户，讳莫如 深" has been translated into "secluded behind closed doors", a very specific and vivid description of the state of detachment among neighbors. Also, the referent of “洞天幽境” is also abstract and mysterious. What place it refers to is unclear which, actually, revealing the essence of Chinese writing and which also accounts for its aesthetic value.

In terms of the sentence, because of the improper loss or placing or collocation of subject, predicate or object in the sentence, which is totally unacceptable to English authorship/readership, some certain changes in the structure and sentence elements are desirable in translation. The original sentence may be called illogical, but in order to rid the derogatory sense, I will call this Chinese writing style superlogical. As described in the first sentence of this paragraph, there are three types of superlogical sentences in Chinese writing, namely loss of subject, predicate, object, etc., misplacing of and improper collocation of these elements. Here are three examples respectively and successively.

(8) 走过几家墙门，都是紧紧爸着，不见一个人影，因为那都是人家的后门。

You will find the doors in the walls close shut without a soul in sight because they are back doors to some households. 
(9) 不论什么时候，你向巷中踅去，都如宁静的黄昏，可以清晰地听到自己的足音

At any hour of day, you can even distinctly hear in the dusk-like quiet your own footsteps.

(10) 那是一种和平的静穆，而不是阴森和肃杀。

There you will experience a kind of peaceful calmness rather than gloomy sternness.

In source sentence (8), there is no subject in the first three clauses. But Chinese readers can understand the sentence according to the context. Through the knowledge of the situation of the verbal communication, the first and third subject must be "you", that is, the reader. And through referring to the earlier utterance, the readers can know that the second missed subject must be "doors". These losses are common in Chinese writing and acceptable to Chinese readers. However, the loss of subject can not be tolerated in English writing. Therefore, "you" and "doors" must be present in the English translation.

In source sentence (9), the original clause “都如宁静的黄昏” reads illogical and the correct arrangement should be “宁 静都如黄昏”. Misplace of elements are common in Chinese poetry for the reason of end rhythm. This sentence may also fares likewise. And in English writing this phenomenon is rare and it needs proper rearrangement. That's why the clause has been translated into "dusk-like quiet".

In the last example, “那是” doesn't have an exact referent (it may refer to the situation, scene or atmosphere), which is common in Chinese essay writing. If literally translated into "that is", it will look queer when collocating with "calmness" and "sternness". Zhang herein made "you" the subject and "experience" the predicate, hence the sentence becomes logical and natural to English readership.

In terms of discourse, it's found that the English translation by Zhang is also as loose-structured as the original text, though the looseness of ST is realized by the non-cohesion between clauses while that of TT by frequent parentheses, especially in the form of adverbial or adverbial clause. The structural looseness can be measured by the average number of commas in a sentence, based on which the structural looseness of ST and TT are compared as follows.

Table 1. Average Number of Commas per Sentence

\begin{tabular}{lll}
\hline & Source Text & Target Text \\
\hline $\begin{array}{l}\text { Average Number of } \\
\text { Commas per Sentence }\end{array}$ & 2.72 & 2.36 \\
\hline
\end{tabular}

As shown in table 1, the average numbers of commas in original Chinese and English translation are largely close, revealing the similar structural looseness of both language versions. This finding has never been indicated by the related literature.

As required by the above-mentioned differences between Chinese and English essay writing, necessary coherence and cohesion devices will make the translation acceptable to English readers who lack the background aesthetic assumption to appreciate Chinese essays. Just as we have mentioned, Chinese discourse prefers juxtaposition of images. Hence, the English translation should have linking words to make it cohesive and device to make it coherent. In this translation, Zhang has used some cohesion words, such as relative clause(the third sentence in paragraph 2, the first sentence in paragraph 3,etc.) and adverbials(over there, from time to time, occasionally, suddenly, etc.). Through these words, the target text becomes a whole. Secondly, the translator also made use of some coherence devices, such as repetition (the word "lane" has been repeated 13 times throughout the text) and pronoun ("it" and "there" have been used to refer to the lane).

Overall, the findings suggest that Zhang's translation of “巷” has made some compromises to deal with the shortage of background assumptions of English readership. On one hand, the looseness of structure is maintained, though by different means, in the English translation, which may seem exotic for English readership but grammatically acceptable. On the other hand, such translation techniques as paraphrasing, explanation, domestication and concretization are employed by Zhang, which explicate the implicit meaning of vocabulary and sentence, thus shifting from Chinese essay readership convention to English essay readership expectation. These findings are quite interesting yet not found in previous literature which mainly focuses on the equivalence of form (e.g., Yu, 2004), content (e.g., Zhu, 2000; Liu, 2001) or aesthetic value (e.g., Lai, 2009).

\section{Evaluation of Zhang's Translation from Rhythm, Style and Spirit}

Fettered by English readers' shortage of background assumption to understand and appreciate the specialty of this Chinese essay, Zhang has tried to make the target text understandable while maintaining the content and loose structure of the source text. Here the paper would like to analyze the translation according to three other criteria crucial to language-specific essay writing and readership convention, namely, rhythm, writing style and spirit, apart from the content and structure.

The rhythm of a text can be analyzed through the length of a segment (a part of sentence or the sentence itself unseparated by any punctuation mark). The reason why the paper analyzes the length of a segment consists in that when you read aloud, the rhythm of the writing can be felt. Here is an example of this analysis. (one "-" refers to a Chinese character or an English word. A segment less than 6 words should be regarded short segment.) When you read the text, 
the short segment can make your emotion and energy intensive and the long segment your emotion and energy flow naturally and slowly.

Source text: 墙里常是人家的竹园，修竹深深，天籁细细；春来时还有几枝娇艳的桃花杏花，娉娉婷婷 ，从墙头殷勤地摇曳红袖，向行人招手。

(Long,short,short,long,short,long,short)

Analysis: it can be seen from these marks that in the source text, short and long segments are interwoven to make the passage sound gentle, yet not too relaxing.

Target text: Inside the walls are residents' gardens with dense groves of tall bamboos as well as soft sounds of nature. In spring, beautiful peach and apricot blossoms atop the walls, like graceful girls waving their red sleeves, will sway hospitably to beckon the pedestrians.

-------------------. --, --------, -------, -------.

(Long,short,long,long,long)

Analysis: The target text is mainly composed of long segments, making this part read much dull and a little bit short of energy. So this translation can be better if the length of sequential segments have been shortened.

Secondly, as for the writing styles of source text, the source text was written with simple but graceful words and phrases. The whole passage sounds a chat between the author and the readers. But the writer also made the simplicity of the text tinged with poetic sensation. Here is an example:

它可能是一条现代的乌衣巷，家家有自己的一本哀乐帐，一部兴衰史，可是重门叠户，讳莫如深，夕

阳影里，野花闲草，燕子低飞，寻受归家。

The first three segments seem that the author is telling a story, full of plain words and expression. But in the last few segments, four words make a segment, enabling them sound poetic lines. Now let's take a look at the translation of this part.

It may be a modern version of Wu Yi Xiang, a special residential area of nobility in the Jin Dynasty southeast of today's Nanjing, where each family, secluded behind closed doors, has its own covered-up story of joys and sorrows, and rise and decline. When the sun is setting, swallows will fly over wild flowers and grass on their way to their nests.

In contrast with the 53 words of the source, the target text has 62 words due to the explanation of Wu Yi Xiang, which makes the text lengthy. Besides, the translation seems a plain description of the lane, suffering from the lack of poetic style.

Last, the spirit of the translation. The "spirit" here means the mental perception and spiritual state invoked onto the reader by the text. As the target text of Zhang has maintained the majority of the original content as well as the original loose structure, the same revelation spirit can also be revealed in his translation. Here is an example.

\section{巷，是是城市建筑艺术中一篇飘逸恬静的散文，一幅古雅冲淡的图画。}

The lane, in terms of the art of urban architecture, is like a piece of prose of gentle gracefulness or a painting of classic elegance and simplicity.

The translation has kept the same idea and spirit of the author. The advantage of the lane has been proposed and the author's preference of it has been fully revealed through both Chinese and English languages.

Therefore, it can be seen that the translation is, as a result of the grammatical cohesion requirement of English language, not relaxed enough in term of rhythm. For the same reason, the writing style is short of some poetic qualities prevalent in the source text. Nevertheless, the spirit of the original essay is maintained through the equivalence of content and loose structure.

In terms of the content, Zhang's translation is definitely adequate for comprehension. But because of the difference of background assumptions, the aesthetic value of English readers differs from Chinese one. So appreciation of the essay translation is itself hard to be achieved among English readership. As each aesthetic value has been largely bound to each language, this gap, I think, can only be bridged by cross-language and cross-culture communication in order to make both Chinese and English people know each other's unique aesthetic value of literature writing.

\section{Conclusion}

This paper starts with the discussion of the biggest obstacle for English readers to comprehend and appreciate English translation of Chinese modern essays, i.e., the shortage of background assumptions to construct necessary cognitive contexts to read Chinese essays, specially reflected in the shortage of expectation towards an essay with ambiguous and implicit meaning, with a loose structure, and with gentle rhythm, poetic style and revelation spirit.

With the unique findings that a compromised strategy has been adopted by Zhang to deal with the shortage of background assumptions in English readership, specifically the shift of ambiguous content, gentle rhythm and poetic style on one hand, and the maintenance of loose structure and revelation spirit on the other, this paper has enriched the present literature by attempting a new perspective, i.e., cognitive context, to study English translation of Chinese modern essays, and also by serving as evaluation reference for English translation of Chinese modern essays. 


\section{Reference}

Han Z.S., Wang J. (2004). Aesthetic Attainment and Experience in Literary Translation: An Evaluation of the Artistic Value of Zhang Peiji's English Translation of “The Sight of My Father's Back”. Foreign Language Education, 3, 6164.

Hu, X. Y., Li L. (2009). Advanced Literary Translation. Beijing: Foreign Language Teaching and Research Press.

Lai X. P. (2009). On the Aesthetic Reproduction of Zhang Peiji's Selected Modern Chinese Essays (Column 3). Central China Normal University Thesis.

Liu, Y. Y. (2001). Zhang Peiji and His Translation. Shanghai Journal of Translators for Science and Technology, 1, 4649.

Ramos, F.Y. (1998). A Decade of Relevance Theory. Journal of Pragmatics, 30(3), 305-345.

Sperber, D., \& Wilson, D. (2001). Relevance: Communication and Cognition. Beijing: Foreign Language Teaching and Research Press.

Tang Y. C. (2001). Cross-sentence Technique in the Translation of Essays: Critique on Selected Modern Chinese Essay by Zhang Peiji. Journal of Beijing International Studies University, 4, 57-62.

Vandepittea, S. (1989). A Pragmatic Function of Intonation: Tone and Cognitive Environment. Lingua, 79(4), $265-297$.

Wang H. T. (2006). From "Implication" to "Explication": Study on English Translation of Chinese Essays from the Perspective of Sino-western Comparative Aesthetics. Foreign Language Teaching, 1, 61-64.

Xiong X. L. (1996). Pragmatics and Cognitive Context. Foreign Language Research, 3, 1-7.

Yu, Y. L. (2004). On Zhang Peiji's Translation Technique to Preserve the Simplicity of Original Text: A Perception of Selected Modern Chinese Essays. Journal of Chongqing Jiaotong University (Social Sciences Edition), 2, 96-98.

Zhang J. (2011). On the Image Retention, Loss and Shift in English Translation of Idioms in Chinese Essay from the Perspective of Dynamic Equivalence: A Case Study of Zhang Peiji's Selected Modern Chinese Essays. Literature and Teaching Papers, 11, 48-50.

Zhu M. H. (2000). New Translation Achievement of Chinese Essays: A Joyful Perception of Zhang Peiji's Selected Modern Chinese Essays. Chinese Translators Journal, 3, 61-63. 